\title{
The Impacts of Regional Regulatory Policies on the Prevention and Control of Chronic Diseases in China: A Mediation Analysis
}

\author{
Huihui Huangfu ${ }^{1,2,+}$, Qinwen Yu ${ }^{1,2,+}$, Peiwu Shi ${ }^{2,3}$, Qunhong Shen ${ }^{2,4}$, Zhaoyang Zhang ${ }^{2,5}$, Zheng Chen ${ }^{2,6}$, \\ Chuan Pu ${ }^{2,7}$, Lingzhong $\mathrm{Xu}^{2,8}$, Zhi Hu ${ }^{2,9}$, Anning Ma ${ }^{2,10}$, Zhaohui Gong ${ }^{2,11}$, Tianqiang $\mathrm{Xu}^{2,12}$, Panshi Wang ${ }^{2,13}$, \\ Hua Wang ${ }^{2,14}$, Chao Hao ${ }^{2,15}$, Qingyu Zhou ${ }^{1,2}$, $\mathrm{Li} \mathrm{Li}^{1,2}$, Chengyue $\mathrm{Li}^{1,2, *}$ and Mo Hao ${ }^{1,2, *}$
}

check for

updates

Citation: Huangfu, H.; Yu, Q.; Shi, P.; Shen, Q.; Zhang, Z.; Chen, Z.; Pu, C.;

Xu, L.; Hu, Z.; Ma, A.; et al. The

Impacts of Regional Regulatory

Policies on the Prevention and

Control of Chronic Diseases in China: A Mediation Analysis. Healthcare 2021, 9, 1058. https://doi.org/ 10.3390/healthcare 9081058

Academic Editor:

Jose Granero-Molina

Received: 27 June 2021

Accepted: 15 August 2021

Published: 18 August 2021

Publisher's Note: MDPI stays neutral with regard to jurisdictional claims in published maps and institutional affiliations.

Copyright: (c) 2021 by the authors. Licensee MDPI, Basel, Switzerland. This article is an open access article distributed under the terms and conditions of the Creative Commons Attribution (CC BY) license (https:// creativecommons.org/licenses/by/ $4.0 /)$.
1 Research Institute of Health Development Strategies, Fudan University, Shanghai 200032, China; 19111020043@fudan.edu.cn (H.H.); 19211020038@fudan.edu.cn (Q.Y.); zhouqingyu@fudan.edu.cn (Q.Z.); yiran_eric@126.com (L.L.)

2 Collaborative Innovation Center of Social Risks Governance in Health, Fudan University, Shanghai 200032, China; pwshi@163.com (P.S.); shenqunhong108@163.com (Q.S.); zhangzhy@nhc.gov.cn (Z.Z.); chenzhengjd@163.com (Z.C.); puchuan68@sina.com (C.P.); lzxu@sdu.edu.cn (L.X.); aywghz@126.com (Z.H.); yxyman@126.com (A.M.); zhgong_zg@163.com (Z.G.); xtq1960@icloud.com (T.X.); wangpanshi03@163.com (P.W.); jswstwh@163.com (H.W.); 18906113216@189.cn (C.H.)

3 Zhejiang Academy of Medical Sciences, Hangzhou 310012, China

4 School of Public Policy and Management, Tsinghua University, Beijing 100084, China

5 Project Supervision Center of National Health Commission of the People's Republic of China, Beijing 100044, China

6 Department of Grassroots Public Health Management Group, Public Health Management Branch of Chinese Preventive Medicine Association, Shanghai 201800, China

7 School of Public Health and Management, Chongqing Medical University, Chongqing 400016, China

School of Public Health, Shandong University, Jinan 250012, China

School of Health Service Management, Anhui Medical University, Hefei 230032, China

10 School of Public Health, Jining Medical University, Jining 272067, China

11 Committee on Medicine and Health of Central Committee of China ZHI GONG PARTY, Beijing 100011, China

12 Institute of Inspection and Supervision, Shanghai Municipal Health Commission, Shanghai 200031, China

13 Shanghai Municipal Health Commission, Shanghai 200031, China

14 Jiangsu Preventive Medicine Association, Nanjing 210009, China

15 Changzhou Center for Disease Control and Prevention, Changzhou 213003, China

* Correspondence: lichengyue@fudan.edu.cn (C.L.); haomo03@fudan.edu.cn (M.H.); Tel.: +86-21-33561022(C.L. \& M.H.)

+ Huihui Huangfu and Qinwen Yu are joint primary authors.

Abstract: Regional regulatory policies (RPs) are a major factor in the prevention and control of chronic diseases (PCCDs) through the implementation of various measures. This study aimed to explore the impacts of RPs on PCCDs, with a focus on the mediating roles of community service. The soundness of the regulatory mechanism (SORM) was used to measure the soundness of RPs based on 1095 policy documents (updated as of 2015). Coverage provided by community service institutions (CSIs) and community health centres (CHCs) was used to represent community service coverage derived from the China Statistical Yearbook (2015), while the number of chronic diseases (NCDs) was used to measure the effects of PCCDs based on data taken from the 2015 China Health and Retirement Longitudinal Study survey. To assess the relationship between SORM, NCDs and community service, a negative binomial regression model and mediation analysis with bootstrapping were conducted. Results revealed that there was a negative correlation between SORM and NCDs. CSIs had a major effect on the relationship between RPs and PCCDs, while CHCs had a partial mediating effect. RPs can effectively prevent and control chronic diseases. Increased effort should also be aimed at strengthening the roles of CSIs and CHCs.

Keywords: regulatory policy; prevention and control of chronic diseases; community service institution; community health centre; mediation analysis 


\section{Introduction}

The prevalence of chronic noncommunicable diseases constitutes a threat to human life, health, and sustainable development [1]. Nowadays, chronic diseases have become the top risk factors for health, accounting for more than $80 \%$ of the 10.3 million annual deaths and $68.6 \%$ of the overall economic burden in China [2]. In this context, several factors have seriously threatened people's health, thus affecting social harmony and the credibility of the Chinese governments, specifically including low awareness rates, long latency, high incidence rates, long clinical courses, high mortality rates, and low control rates [2,3]. These issues demonstrate the need for increased attention on chronic disease, particularly to reduce the risk of illness while improving the overall quality of life.

Chronic diseases are preventable and controllable. Interventions on the prevention and control of chronic diseases (PCCDs) are known to aid in early detection, diagnosis, and treatment initiatives while reducing related economic burdens [4]. Meanwhile, regulatory policies (RPs) can improve the rate of service coverage by promoting the implementation of prevention measures [5], thereby constituting a major source of control for PCCDs. Extensive research has also shown that the soundness of RP has a significant impact on PCCDs [6]. For example, Huang Jianming et al. [7] found that strong community RPs can be used to improve several problematic issues among patients, including hypertension, while Locke et al. [8] demonstrated that RPs had positive effects on the management of diabetic patients in Canada, and Francisco et al. [9] proposed the implementation of multifunctional services designed to monitor and manage COPD patients based on the effectiveness of a chronic disease management model.

The PCCDs is a common and effective practice in many communities [10]. Specifically, in China, community service institutions (CSIs) have become increasingly valuable for PCCDs since the new health care reforms in 2009 [11,12]. CSIs are initiated by the government and mainly responsible for public-welfare-based social service activities; the service scope mainly includes medical care, pensions, and living [13]. Similarly, community health centres (CHCs), which are a smaller unit of CSIs, provide medical and health services and implement important strategies for PCCDs at the community level [14]; this was also observed by Wong [15]. CHCs help to detect risk factors, provide health education, and prevent chronic diseases [16], as has also been reported by Kim and Sharma [17,18]. Therefore, CSIs and CHCs are important factors in promoting health and preventing chronic diseases.

To improve PCCDs, it is necessary to understand the relationship between RPs, CSIs, CHCs, and PCCDs. According to the Donabedian's model, which contains structure, process, outcome, and the relationship among them (structure-process-outcome) [19], RPs (structure) influence the effects of PCCDs (outcome) through implementation at the process level. CSIs and CHCs, as the 'gatekeepers' of community members and 'vanguards' of disease prevention and control, provide social support and prevention services, which can effectively control the spread and deterioration of chronic diseases (process) [20]. The two can work together to implement the chronic disease control. We, therefore, assumed that the relationship between RPs and PCCDs could be explained based on both the coverage of CSIs and CHCs. Many studies have adopted mediation analysis. For instance, Vedanthan et al. found that community health workers mediated hypertension care policy and the control of blood pressure [21]. Chen et al. reported that social capital has an effect on physical activity and nutrition [22]. However, no available study in the context of the relationship between RPs and PCCDs and the pathways has adopted mediation analysis. Therefore, this study aimed to fill this gap by exploring the association between RPs and PCCDs, with a focus on whether CSIs and CHCs mediated this relationship. 


\section{Materials and Methods}

\subsection{Study Design}

The study setting included 31 provinces in China. A mediation analysis was conducted to determine whether CSIs and CHCs mediated the relationship between RPs and PCCDs. We, therefore, hypothesised the following (Figure 1):
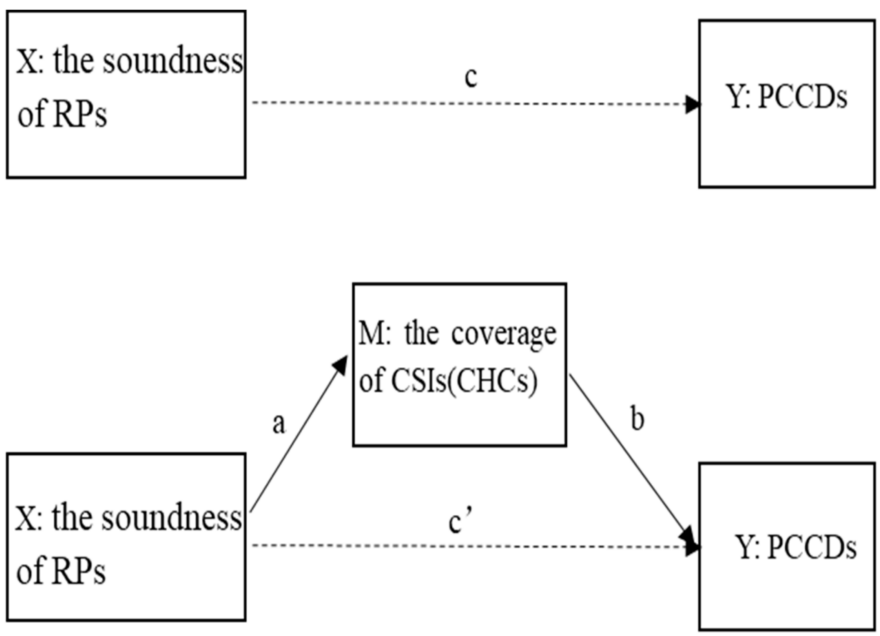

Figure 1. Mediating model for this study's conceptual framework. Abbreviations: RPs, regulatory policies; CSIs, community service institutions; CHCs, community health centres; PCCDs, prevention and control of chronic diseases.

Hypothesis 1a (H1a). The soundness of RPs has a positive impact on the coverage of CSIs (CHCs).

Hypothesis $\mathbf{1 b} \mathbf{( H 1 b )}$. The coverage of CSIs (CHCs) has a positive impact on PCCDs.

Hypothesis 1c (H1c). The soundness of RPs has a positive impact on PCCDs.

\subsection{Measurements}

\subsubsection{The Soundness of RPs}

We constructed the soundness of the regulatory mechanism (SORM) to evaluate the soundness of RPs. The SORM should have at least three characteristics: comprehensiveness, authority, and implementation [23]. Here, the comprehensiveness of the mechanism requires the coverage of essential elements in the policies for PCCDs and clearly outlined responsibilities for each of the departments covered, based on the services they provide [24]. The authority of the mechanism requires issuance of documents by authorities (legislature, government, health commission, etc.) to reflect the importance of RPs. Furthermore, the mechanism requires supervision by external restraint mechanisms for the implementation of the policies [25]. Therefore, four quantitative indicators were adopted. These were named regulatory element coverage rate (RECR), departmental responsibilities clarity rate (DPCR), regulatory mechanism authority rate (RMAR), and accountability mechanism clarity rate (AMCR), and their definitions are detailed in Table 1 [23]. Additionally, SORM was measured based on the sum of the weights of the four quantitative indicators [26]. The study assumed that the higher the SORM (range from 0 to 100 percent), the better the soundness of RPs [26]. 
Table 1. Evaluation indicators for the soundness of RPs.

\begin{tabular}{|c|c|c|}
\hline Characteristics & $\begin{array}{l}\text { Quantitative } \\
\text { Indicators }\end{array}$ & Definition of Indicators \\
\hline \multirow[t]{2}{*}{ Comprehensiveness } & $\operatorname{RECR}(\%)$ & $\begin{array}{l}\text { The proportion of the number of regulatory } \\
\text { elements covered in a city's chronic disease health } \\
\text { policy document collection to the } 25 \text { required } \\
\text { elements }\end{array}$ \\
\hline & DPCR (\%) & $\begin{array}{l}\text { The proportion of the number of departments with } \\
\text { clear and measurable responsibilities to the } 22 \\
\text { departments that should be included in PCCDs }\end{array}$ \\
\hline Authority & RMAR (\%) & $\begin{array}{l}\text { The proportion of the number of authority of } \\
\text { government branches and regulatory mechanism } \\
\text { document sets to the total required }\end{array}$ \\
\hline Implementation & AMCR (\%) & $\begin{array}{l}\text { The proportion of the number of departments with } \\
\text { clearly defined monitoring agencies and } \\
\text { accountabilities to the } 22 \text { departments that should } \\
\text { be included in PCCDs }\end{array}$ \\
\hline
\end{tabular}

Abbreviations: RPs, regulatory policies; RECR, regulatory element coverage rate; DPCR, departmental responsibilities clarity rate; RMAR, regulatory mechanism authority rate; $\mathrm{AMCR}$, accountability mechanism clarity rate; PCCDs, prevention and control of chronic diseases.

\subsubsection{PCCDs}

The number of chronic diseases (NCDs) was used to evaluate the effects of PCCDs. In this regard, we defined chronic diseases as those with long durations and slow development [27]. A total of 13 chronic diseases were considered according to the standards of data collection presented in the China Health and Retirement Longitudinal Study (CHARLS), including heart disease, stroke, malignant tumour, asthma, chronic obstructive pulmonary disease, diabetes, hypertension, dyslipidaemia (WHO) [28], memory-related diseases (e.g., Alzheimer's disease, brain atrophy, Parkinson's disease), kidney disease (excluding tumours and cancers), arthritis/rheumatism, liver disease (excluding fatty liver, tumours, and cancers), and chronic gastroenteritis (ICD-11) [28].

\subsubsection{The Coverage of CSIs and CHCs}

The coverage of CSIs was measured using the coverage rate of the community service institutions (CRCSI), while the coverage of CHCs was measured using the coverage rate of the community health centres (CRCHC).

\subsection{Data Collection}

Data were collected from the quantitative analysis of policy contents (which contributed to the soundness of RPs), CHARLS (contributed to PCCDs), and China Statistical Yearbook (contributed to CSIs and CHCs).

We first obtained SORM data from policy contents (the coding template is shown in Table A1). Here, we collected a range of policy documents, which were either publicly available or extracted with permission [29] from official websites, including those run by relevant government entities and public health agencies focused on chronic diseases in China (updated as of 2015). The types of policy documents included laws, regulations, plans, guidelines, and others, resulting in a total of 1095 documents from 31 provinces in China.

This study's researchers were previously trained and thus understood the standardised methods for collecting necessary documents. The coding information mainly included two components, the first of which consisted of basic information related to the documents, including their official names, types, year of publication, and department or institution of publication, while the second consisted of contents related to RPs aimed at chronic disease, including content forms (e.g., long-term goals and short-term goals) [25], responsibilities, work contents, tasks, assessment indicators, assessment requirements, and accountabil- 
ity. We analysed the credibility of the data collection process via the test-retest reliability method with intraclass correlation coefficient (ICC). After two experienced researchers conducted the retest, the ICC was found to be 0.997 ; as this was greater than 0.75 , the data collection process was of high credibility.

Next, NCDs data were drawn from the 2015 CHARLS survey and set as dependent variables. CHARLS was a longitudinal survey that aimed to be representative of the residents in mainland China aged 45 and older, with no upper age limit [30]. Multi-stage stratified probability-proportional-to-size sampling was used to conduct the survey, which randomly selected 150 counties/districts and 450 villages/resident committees, thereby covering 19,000 individuals living in 12,400 households [31] from 28 provinces (data from Hainan, Ningxia, and Tibet were missing), thus collecting a high-quality nationally representative sample [31-34]. The CHARLS database includes a series of topics, such as demographics, family structure/transfer, health status and functioning, health care and insurance, work, retirement and pension, income and consumption, and community-level information [33]. Subjects with missing or unreasonable responses were excluded from analysis, thus resulting in a final sample size of 16,693.

Finally, CRCSI and CRCHC data were collected from the 2015 China Statistical Yearbook and set as mediating variables.

\subsection{Statistical Analysis}

Data were analysed using both EXCEL 2019 (Microsoft, Redmond, WA, USA) and Stata 14.0 (Stata Corp., College Station, TX, USA).

To avoid an inherent reverse-causality issue, considering that chronic diseases are long duration illnesses [27], we used past RPs to reflect the accumulation of chronic diseases over a long timeframe. The soundness of RPs is a gradual improvement process; therefore, we used the policy contents (updated as of 2015) to comprehensively reflect past regulatory effects. As a result of the accessibility of NCDs, data from 28 provinces were used for descriptive statistics and mediation analysis.

To determine the mediating roles of the CRCSI and CRCHC on the relationship between RPs and PCCDs, we used Spearman's correlation analysis to assess the multicollinearity between SORM, CRCHC, CRCSI, and NCDs. Multicollinearity meant that highly correlated variables $(r>0.90)$ or mediation variables that were not correlated with either SORM or NCDs were excluded from the mediation analyses [22].

Subsequently, the following negative binomial regression model was established to analyse the relationship between RPs and PCCDs, as the outcome variable is a count variable with over-dispersed distribution (alpha 95\%CI $(0.27,0.31)$ ).

$$
\ln \left(\lambda_{\mathrm{i}}\right)=\beta_{0}+\text { cSORM }_{\mathrm{i}}+\delta_{0} \mathrm{X}_{\mathrm{i}}+\gamma_{0} \text { Province }_{\mathrm{i}}+\varepsilon_{\mathrm{i}}
$$

Number of chronic diseases (NCDs) was set as the dependent variable, and $\lambda_{i}$ was the expected count of NCDs. SORM $\mathrm{i}_{\mathrm{i}}$ was set as the independent variable. $\mathrm{X}_{\mathrm{i}}$ was used as a control variable at the individual level, including age, gender, marital status, education attainment, annual household income per capita, medical insurance, pension insurance, smoking, and drinking. Province ${ }_{i}$ was used as a control variable at the provincial level, including GDP per capita (reflective of the regional economic level), and the proportion of the population over 65 years of age. $\varepsilon_{i}$ were the residuals.

Finally, we conducted a mediation analysis with bootstrapping using 5000 replications [35] and bias-corrected and accelerated confidence interval (BCa CI) [36] to examine whether community service mediated the relationship between SORM and NCD. The mediation method required the following conditions: (1) SORM was significantly associated with NCD (total effect; c coefficient), (2) SORM was significantly associated with CRCSI (CRCHC) (a coefficient), (3) when controlling for SORM, CRCSI (CRCHC) was significantly associated with NCD (b coefficient), (4) the relationship between SORM and NCD was reduced (direct effect, $\mathrm{c}^{\prime}$ coefficient) when controlling for CRCSI (CRCHC) (indirect effect, 
$\left.a^{*} b\right)$. The proportions mediated were determined by dividing the indirect effect $\left(a^{*} b\right)$ by the total effect (c coefficient).

\section{Results}

\subsection{Baseline Characteristics}

Table 2 shows the SORM of China and variables at the provincial level in 2015, as used in this study. The SORM was $9.70 \%$, thus indicating substantial room for improvement in regard to the RPs aimed at chronic disease. DPCR was $4.92 \%$, thus indicating that responsibilities should be more clearly defined. The median value of AMCR was $0.55 \%$, thus indicating the lack of an external accountability mechanism in each department, which restricted the effectiveness of PCCDs. The mean of CRCSI (58.46\%) was higher than the mean of CRCHC (6.72\%).

Table 2. Characteristics of SORM and variables at the provincial level in 2015.

\begin{tabular}{|c|c|c|}
\hline Indicators & $\begin{array}{c}\text { Mean Value/Median } \\
\text { Value }\end{array}$ & SD/IQR \\
\hline SORM (\%) & 9.70 & 3.67 \\
\hline RECR (\%) & 37.84 & 10.32 \\
\hline DPCR $(\%)$ & 4.92 & 4.29 \\
\hline RMAR (\%) & 23.55 & 6.91 \\
\hline $\operatorname{AMCR}(\%)^{1}$ & 0.55 & $(0,1.85)$ \\
\hline \multicolumn{3}{|l|}{ Community service } \\
\hline $\mathrm{CRCHC}(\%)$ & 6.72 & 6.20 \\
\hline CRCSI (\%) & 58.46 & 54.00 \\
\hline \multicolumn{3}{|l|}{ Economic and aging level } \\
\hline GDP per capita (thousand yuan) & 54.61 & 24.00 \\
\hline Proportion of population over 65 years of age (\%) & 10.35 & 1.70 \\
\hline
\end{tabular}

Table 3 shows baseline characteristics of the study variables. The mean participant age was 61 years, and there was a slightly higher proportion of females $(51.85 \%$ vs. $48.15 \%$ males). A total of $27.36 \%$ of participants did not suffer from chronic disease. However, more than $70 \%$ had at least one chronic disease, with some suffering from multiple chronic diseases. 
Table 3. Variable descriptions $(n=16,693)$.

\begin{tabular}{|c|c|c|c|}
\hline Variables & Category & $\begin{array}{c}\text { Mean } \\
\text { (Median)/n }\end{array}$ & SD (IQR)/\% \\
\hline \multirow[t]{6}{*}{ NCDs } & 0 & 4567 & 27.36 \\
\hline & 1 & 4481 & 26.84 \\
\hline & 2 & 3379 & 20.24 \\
\hline & 3 & 2023 & 12.12 \\
\hline & 4 & 1162 & 6.96 \\
\hline & $\geq 5$ & 1081 & 6.48 \\
\hline \multicolumn{4}{|l|}{ Control variables } \\
\hline Age (years) & & 61 & 10.01 \\
\hline \multirow[t]{2}{*}{ Sex } & Male $=1$ & 8037 & 48.15 \\
\hline & Female $=2$ & 8656 & 51.85 \\
\hline \multirow[t]{2}{*}{ Registered residence } & Town $=1$ & 3547 & 21.25 \\
\hline & Rural $=0$ & 13,146 & 78.75 \\
\hline \multirow{2}{*}{ Marital status } & Married = 1 & 13,349 & 79.97 \\
\hline & Other $=0$ & 3344 & 20.03 \\
\hline \multirow[t]{3}{*}{ Education attainment } & Elementary school and below $=1$ & 4900 & 29.35 \\
\hline & Junior high school $=2$ & 5665 & 33.94 \\
\hline & Senior high school and above $=3$ & 6128 & 36.71 \\
\hline \multirow[t]{2}{*}{ Medical insurance } & Yes $=1$ & 15,234 & 91.26 \\
\hline & $\mathrm{No}=0$ & 1459 & 8.74 \\
\hline \multirow[t]{2}{*}{ Pension insurance } & Yes $=1$ & 14,696 & 88.04 \\
\hline & No $=0$ & 1997 & 11.96 \\
\hline \multirow[t]{2}{*}{ Drinking } & Yes $=1$ & 7733 & 46.33 \\
\hline & $\mathrm{No}=0$ & 8960 & 53.68 \\
\hline \multirow[t]{2}{*}{ Smoking } & Yes = 1 & 6912 & 41.41 \\
\hline & No $=0$ & 9781 & 58.59 \\
\hline Annual household income per capita(yuan) ${ }^{1}$ & & 6993.50 & $(2470,17,000)$ \\
\hline
\end{tabular}

${ }^{1}$ The indicator was expressed as the median (IQR). Abbreviations: NCDs, number of chronic diseases; SD, standard deviation; IQR, interquartile range.

\subsection{Correlation Analysis}

Table 4 summarises the relationships between variables using Spearman's correlation analysis. SORM was positively correlated with both CRCHC $(r=0.331, p<0.01)$ and CRCSI $(r=0.473, p<0.01)$. Conversely, NCD exhibited significant negative correlations with SORM ( $\mathrm{r}=-0.029, p<0.01)$, CRCHC $(\mathrm{r}=-0.049, p<0.01)$, and CRCSI $(\mathrm{r}=-0.059$, $p<0.01)$.

Table 4. Spearman's correlation analysis on the relationships between SORM, CRCHC, CRCSI, and NCD per capita.

\begin{tabular}{cccc}
\hline Variables & SORM & CRCHC & CRCSI \\
\hline CRCHC & $0.331^{* * *}$ & & \\
CRCSI & $0.473^{* * *}$ & $0.396^{* * *}$ & $-0.059^{* * *}$ \\
NCD per capita & $-0.029^{* * *}$ & $-0.049^{* * *}$ &
\end{tabular}

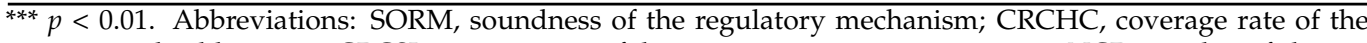
community health centres; CRCSI, coverage rate of the community service institutions; NCD, number of chronic diseases.

\subsection{Regression Analysis}

Table 5 summarises the relationship between SORM and NCDs. SORM exhibited a significant negative correlation with NCD $(\beta=-0.014, p<0.01)$. When controlling for variables at the provincial level, we found that SORM was still significantly associated with $\operatorname{NCD}(\beta=-0.010, p<0.01)$. In this case, SORM had a positive effect on the NCD. 
Table 5. Negative binomial regression analysis of the effects of SORM on NCDs (per capita).

\begin{tabular}{|c|c|c|c|c|}
\hline \multirow{2}{*}{ Variables } & \multicolumn{2}{|c|}{ Model 1} & \multicolumn{2}{|c|}{ Model 2} \\
\hline & $\beta$ & SE & $\beta$ & SE \\
\hline SORM & $-0.014^{* * *}$ & 0.002 & $-0.010^{* * *}$ & 0.003 \\
\hline \multicolumn{5}{|l|}{ Control variables (individual level) } \\
\hline Age & $0.019 * * *$ & 0.001 & $0.019^{* * *}$ & 0.001 \\
\hline Sex & $0.211^{* * *}$ & 0.023 & $0.213^{* * *}$ & 0.023 \\
\hline Registered residence & $0.136^{* * *}$ & 0.019 & $0.139 * * *$ & $(0.019)$ \\
\hline Marital status & 0.011 & 0.019 & 0.011 & $(0.019)$ \\
\hline $\begin{array}{c}\text { Education attainment } \\
\text { (Reference group: } \\
\text { elementary school and below) }\end{array}$ & \multicolumn{3}{|c|}{$\begin{array}{l}\text { (Reterence group: } \\
\text { elementary school and below) }\end{array}$} & \\
\hline Junior high school & $0.082 * * *$ & 0.019 & $0.081^{* * *}$ & 0.019 \\
\hline Senior high school and above & 0.028 & 0.022 & 0.031 & 0.022 \\
\hline Log Annual household income per capita & $-0.016^{* * *}$ & 0.004 & $-0.015^{* * *}$ & 0.005 \\
\hline Medical insurance & $0.139 * * *$ & 0.028 & $0.136^{* * *}$ & 0.028 \\
\hline Pension insurance & $0.049 *$ & 0.025 & $0.045^{*}$ & 0.025 \\
\hline Drinking & $0.037^{* *}$ & 0.017 & $0.028 *$ & 0.017 \\
\hline Smoking & $0.057^{* * *}$ & 0.021 & $0.065^{* * *}$ & 0.021 \\
\hline \multicolumn{5}{|l|}{ Control variables (provincial level) } \\
\hline Log GDP per capita & & & $-0.094^{* * *}$ & 0.026 \\
\hline Proportion of population over 65 years of age & & & $0.028^{* * *}$ & 0.005 \\
\hline alpha $95 \% \mathrm{CI}$ & \multicolumn{2}{|c|}{$(0.270,0.311)$} & \multicolumn{2}{|c|}{$(0.267,0.308)$} \\
\hline
\end{tabular}

*** $p<0.01,{ }^{* *} p<0.05, * p<0.1$. Abbreviations: SORM, soundness of the regulatory mechanism; NCDs, number of chronic diseases.

\subsection{Mediation Effects}

Table 6 shows the mediating effects of CRCHC and CRCSI. There was a negative correlation between SORM and NCD (path: total effect, $\beta=-0.014 ; 95 \%$ CI: -0.022 , -0.006). Next, both CRCHC (path: indirect effect, $\beta=-0.002 ; 95 \% \mathrm{CI}:-0.003,-0.001$ ) and CRCSI (path: indirect effect, $\beta=-0.006 ; 95 \%$ CI: $-0.008,-0.005$ ) mediated the relationship between SORM and NCD. However, the bootstrap analysis showed that each played different mediating roles. $\mathrm{CRCHC}$ had a partial mediating effect (11.31\% of the total), with the $95 \%$ CI of the direct effects in model B including the value of zero, while CRCSI had a major mediating effect $(45.42 \%$ of the total).

Table 6. Bootstrap analysis of the mediation effects.

\begin{tabular}{|c|c|c|c|c|c|}
\hline Model & Path & $\beta$ & SE & $95 \%$ CI & $\begin{array}{l}\text { Promotion } \\
\text { Mediated }\end{array}$ \\
\hline & Total effect & $-0.014^{* * *}$ & 0.004 & $-0.022,-0.006$ & \\
\hline A: CRCHC & $\begin{array}{l}\text { Direct effect } \\
\text { Indirect effect }\end{array}$ & $\begin{array}{l}-0.012 * * * \\
-0.002 * * *\end{array}$ & $\begin{array}{l}0.004 \\
0.001\end{array}$ & $\begin{array}{l}-0.021,-0.004 \\
-0.003,-0.001\end{array}$ & $11.31 \%$ \\
\hline B: CRCSI & $\begin{array}{l}\text { Direct effect } \\
\text { Indirect effect }\end{array}$ & $\begin{array}{l}-0.008^{*} \\
-0.006^{* * *}\end{array}$ & $\begin{array}{l}0.004 \\
0.001\end{array}$ & $\begin{array}{c}-0.016,0.001 \\
-0.008,-0.005\end{array}$ & $45.42 \%$ \\
\hline
\end{tabular}

Bootstrapped standard errors in parentheses ${ }^{* * *} p<0.01,{ }^{*} p<0.1$. We also controlled for age, gender, marital status education attainment, annual household income per capita, medical insurance, pension insurance, smoking, drinking, GDP per capita, and proportion of the population over 65 years of age. Abbreviations: CRCHC, coverage rate of the community health centres; CRCSI, coverage rate of the community service institutions.

\section{Discussion}

This study examined the relationship between RPs and PCCDs, with a focus on the mediating roles of the coverage of CSIs and CHCs. Both policy content and mediation analysis were conducted, demonstrating that RPs had positive impacts on PCCDs, while both the coverage of CSIs and CHCs mediated the relationship between RPs and PCCDs. Further, better SORM was associated with less NCD per capita, which showed that RPs and PCCDs were more effective in regions with those qualities. This supports the rele- 
vant literature. For example, previous research has shown that the soundness of RPs can effectively improve unhealthy lifestyles among patients with hypertension [7]. Similarly, the soundness of RPs has also been found to promote maternal and child health [25]. In this context, regions with better RPs have more effective PCCDs, particularly when RPs are more comprehensive and cover a range of aspects, such as diet management and the living environment. Meanwhile, the accountability mechanism is implementable when relevant departments have clear responsibilities. For example, the government may raise taxes on alcohol and tobacco while reducing the available subsidies for unhealthy foods. Environmental protection standards should also be strictly implemented by environmental protection departments. In other areas, the Landscaping bureau is responsible for the construction of urban green spaces, while the Food and Drug Administration must supervise the food processing industry to reduce the use of salt and trans-fatty acids [37]. Especially when combined, these efforts can further prevent and control chronic disease. It is therefore necessary to establish a long-term working mechanism for managing general health and chronic disease. Efforts must be directed at improving the contents and processes of management services, clarifying departmental responsibilities, strengthening the departmental accountability mechanism, and establishing a management model targeted at the integrated prevention, treatment, and management of chronic disease [38].

Our study indicated that $\mathrm{CHCs}$ played a partial mediating role in the relationship between RPs and PCCDs. As subsections of CSIs, CHCs were particularly effective entities for controlling chronic disease [39]. Previous studies have shown that communities provide better social environments, which facilitate access to elements such as health education, early detection, early treatment, comprehensive management [40], and rehabilitation exercises [41], all of which can further aid in the control of chronic disease. CHCs play important roles due to important aspects of social mobilisation and policy support [42], as they work as the 'gatekeeper' of residents and 'vanguard' of prevention and control [20]. Community health personnel also maintain closer relationships with residents, thus providing the health management [43] needed to ensure positive health outcomes. In this regard, China should establish and improve RPs specifically aimed at PCCDs, with a strong focus on the incentive mechanism, thus allowing community health personnel to achieve a balance between income and expenditures on capitation fees. In addition, the government should allocate special chronic disease management funds within the per capita public health funds in order to implement a pay-for-performance provision for community health personnel [44]. This will enhance enthusiasm among community health personnel while continuously strengthening the effects of PCCDs in various regions of China.

We found that CSIs played a major mediating role in the relationship between RPs and PCCDs. The mediation analysis specifically demonstrated that the coverage of CSIs had a more significant mediating effect than that derived from the coverage of CHCs. This may be due to the widespread nature of social factors that affect chronic disease, thus indicating that PCCDs should focus on cooperating with other fields at all levels. As effective carriers for PCCDs, CSIs often undertake multiple responsibilities in addition to those related to health services [10], such as providing social support at community service centres [44], promoting physical exercise for the elderly in designated activity rooms [45], employing community healthcare workers [46], providing medical care through community pension service centres [47], and offering health self-education through reading rooms or at community schools [48]. As a specific example, studies have shown that physical exercise, social interaction, access to care, and community service have positive effects on health of older patients with diabetes [49]. Along with the advantages provided through community-based joint prevention and control, these factors play important roles in the context of PCCDs. Based on the idea that health should be included in all policies, we should consider that effective PCCDs may require coordinated participation from multiple stakeholders [50]. In addition to improving CHCs, we should also pay more attention to how multiple departments work as a joint force in the prevention and reduction of chronic disease. 
The results of our policy content analysis showed that SORM requires improvement in China. There are no relevant laws for PCCDs, owing to which the government is unable to ensure adherence. There is also a great deal of room to develop completeness among regulatory elements, including the policymaking process, service provisions, the division of responsibility, and information monitoring and evaluation [24]. In addition, the implementation of PCCDs is restricted by factors such as the lack of organisations or professionals and effective multi-department coordination mechanisms [6]. Further, the responsibilities of relevant departments are not sufficiently clear, thereby resulting in the non-assessment of business objectives and the failure to play a positive role in guiding relevant work. Departments also lack an external supervisory mechanism that could effectively restrict their actions. In this context, the government should work to improve laws and regulations related to the control of chronic disease, enhance the contents of chronic disease management, clarify departmental responsibilities, and improve the regulatory and accountability mechanisms. In sum, these efforts will help prevent and reduce the occurrence of chronic disease.

This study also had some limitations. First, the policy content analysis was primarily aimed at evaluating RPs. In the future, relevant verification information should be collected through additional investigations. Second, mediating roles may not be limited to CSIs and CHCs, as both the quality and type of service may affect the relationship between RPs and PCCDs. Third, the factors affecting PCCDs are not limited to RPs; they also include organisations, resources, and the environment. These factors are interrelated and interact within the health system. Additional research is needed to verify the nature of those relationships.

\section{Conclusions}

This study found that CSIs and CHCs play mediating roles in the relationship between RPs and PCCDs. In this regard, RPs can promote the effects of PCCDs, meaning that improved RPs will promote health while preventing and controlling disease. Moreover, increased attention should be placed on the specific roles played by CSIs and CHCs.

Author Contributions: Conceptualization, C.L. and M.H.; methodology, P.S., Q.S., Z.Z., Z.C., C.P., L.X., Z.H., A.M., Z.G., T.X., P.W., H.W. and C.H.; software, H.H., Q.Y. and Q.Z.; validation, H.H., Q.Y. and L.L.; formal analysis, H.H., Q.Y. and C.L.; data curation, H.H., Q.Y., C.L. and M.H.; writingoriginal draft preparation, H.H. and Q.Y.; writing—review and editing, Q.S., Z.Z., Z.C., C.P., L.X., C.L. and M.H.; supervision, Z.H., A.M., Z.G., T.X., P.W., H.W., C.H., C.L. and M.H.; project administration, C.L. and M.H.; funding acquisition, C.L. and M.H.; H.H. and Q.Y. contributed equally to this work. All authors have read and agreed to the published version of the manuscript.

Funding: This research was funded by the Three-Year Action Plan of Shanghai Municipality Strengthens Public Health System Construction, grant number GWIV-32 and GWV-12, the National Natural Science Foundation of China, grant number 72074048 and 71774031, and the Shanghai Foundation for Talents Development, grant number 2020128. The funding bodies played no role in study design, the collection, analysis, and interpretation of data, or in writing the manuscript for publication.

Institutional Review Board Statement: Not applicable.

Informed Consent Statement: Not applicable.

Data Availability Statement: Some data used in this study are publicly available at http://charls. pku.edu.cn/index/zh-cn.html (accessed on 13 September 2019) and http:/ / www.stats.gov.cn/tjsj/ ndsj/2016/indexch.htm (accessed on 26 September 2019). The rest of the data are available from the corresponding author on reasonable request.

Acknowledgments: We are very grateful for the guidance of teachers and the support and help of team members. We also thank Tsinghua University, Shandong University, Huazhong University of Science and Technology, Anhui Medical University, Nanjing Medical University, Harbin Medical University, Chongqing Medical University, Xinjiang Medical University, Weifang Medical University, and Jining Medical University for their support of data collection. 
Conflicts of Interest: The authors declare no conflict of interest.

\section{Abbreviations}

PCCDs prevention and control of chronic diseases

RPs regulatory policies

CSIs community service institutions

CHCs community health centres

SORM soundness of the regulatory mechanism

RECR regulatory element coverage rate

DPCR departmental responsibilities clarity rate

RMAR regulatory mechanism authority rate

AMCR accountability mechanism clarity rate

NCDs number of chronic diseases

ICC intraclass correlation coefficient

CRCSI coverage rate of the community service institutions

$\mathrm{CRCHC}$ coverage rate of the community health centres

SD standard deviation

IQR interquartile range

\section{Appendix A}

Table A1. Coding Template.

\begin{tabular}{|c|c|c|}
\hline Name-ID & Description & Coding \\
\hline $\begin{array}{l}\text { Comprehensive } \\
\text { coverage of regulatory } \\
\text { elements-A1 }\end{array}$ & $\begin{array}{l}\text { Record the content form } \\
\text { involved in the file set }\end{array}$ & $\begin{array}{l}\text { 1-long-term goal (over five years) } \\
\text { 2--short-term goal (under five years) } \\
\text { 3-put forward tasks and measure around the goal } \\
\text { 4--policymaking } \\
\text { 5-service (intervention) content } \\
\text { 6--service (intervention) scope (region, population) } \\
\text { 7-service process } \\
\text { 8-operational norms } \\
\text { 9--technical standards } \\
\text { 10-institutional settings standards } \\
\text { 11-personnel allocation standards } \\
\text { 12-professional qualification standards } \\
\text { 13-funding sources } \\
\text { 14-funding standards } \\
\text { 15-funds guarantee measures } \\
\text { 16--material price standards } \\
\text { 17-material supply management norms } \\
\text { 18-information system construction standards } \\
\text { 19-information monitoring standards } \\
\text { 20-division of responsibility } \\
\text { 21-monitoring and control mode } \\
\text { 22-performance indexes and standards } \\
\text { 23-reward and punishment measures } \\
\text { 24-department coordination modes } \\
\text { 25-evaluation indicators and standards }\end{array}$ \\
\hline
\end{tabular}


Table A1. Cont.

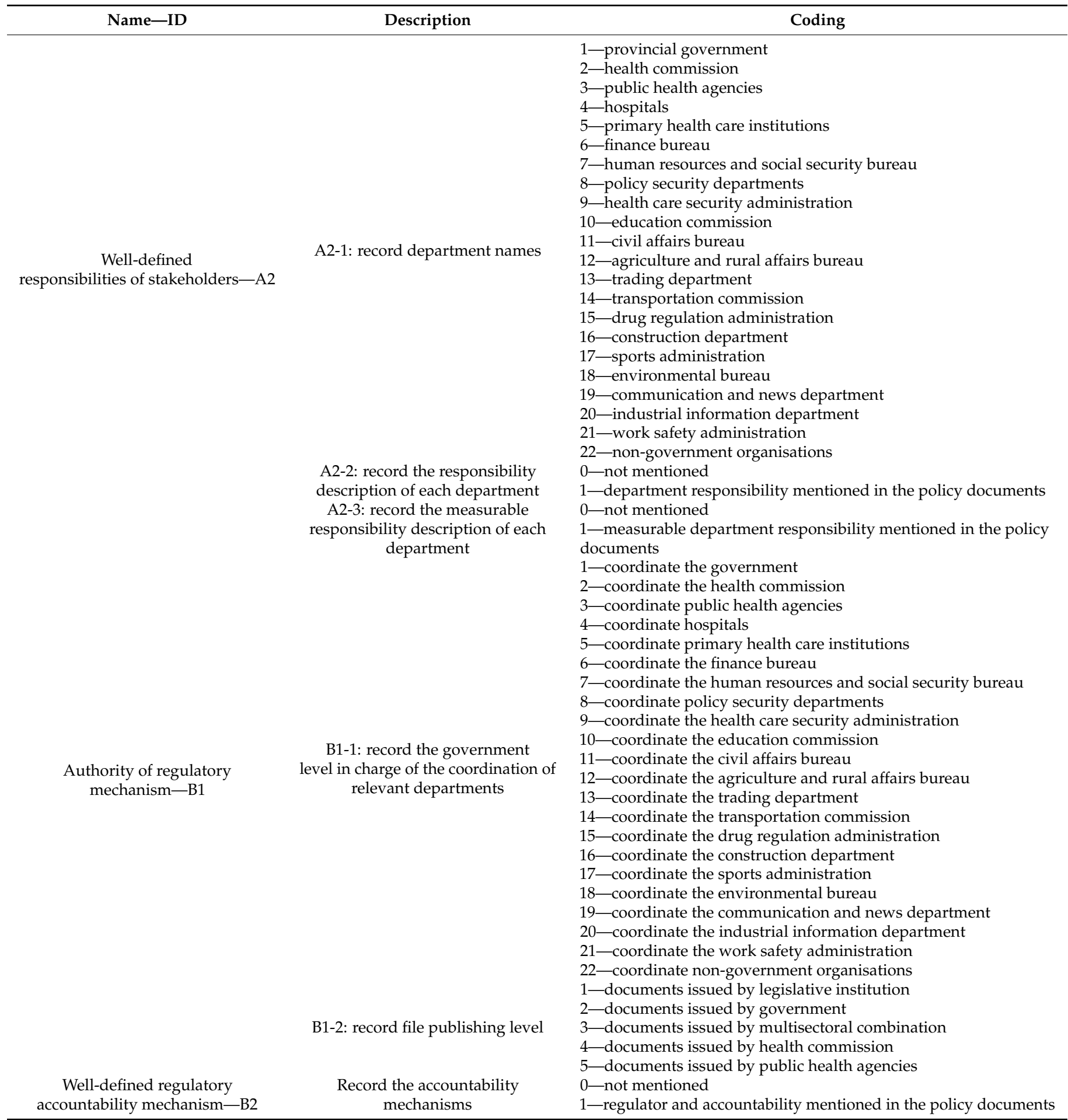

\section{References}

1. Health China Action Promotion Committee. Healthy China Action (2019-2030). Available online: http://www.gov.cn/xinwen/ 2019-07/15/content_5409694.htm (accessed on 15 July 2019).

2. Human Development Unit of East Asia and Pacific Region. Toward a Healthy and Harmonious Life in China: Stemming the Rising Tide of Non-Communicable Diseases; World Bank: Washington, DC, USA, 2011; pp. 1-8.

3. Lv, L.T.; Deng, S.L. The current status and development strategies of chronic disease management in China. Chin. J. Health Policy 2016, 9, 1-7. 
4. World Health Organization. Transforming our World: The 2030 Agenda for Sustainable Development. Available online: https://sdgs.un.org/2030agenda (accessed on 21 October 2019).

5. Li, A.L.; Zhang, Y.; Bai, Y.M.; Shao, Y.Q.; Yuan, H.; Zhang, Y.Y.; Xiang, F.; Sheng, Y.W.; Hu, Z.H.; Peng, H. Analysis on the development process of important policies related to community chronic disease prevention and control. Chin. J. Prev. Control Chronic Dis. 2017, 25, 305-308.

6. Wang, R.Y.; He, Z.Y.; Zhao, W.W.; Wang, Y.Y.; Zhang, M.; Sun, M.M. Research progress of chronic disease management. Chin. Gen. Pract. 2016, 19, 1989-1993.

7. Huang, J.M.; Hu, X.F. Prevention and control effect of community chronic disease monitoring and tracking management mode of community chronic disease monitoring and tracking management mode on hypertension patients. Qingdao Med. J. 2018, 50, 280-282.

8. Locke, K.; Noseworthy, R.; Davies, A. Management of diabetes mellitus in nova-scotia Micmac communities. J. Can. Diet Assoc. 1993, 54, 92-96.

9. Pozo, F.D.; Toledo, P.D.; Jiménez, S.; Hernando, M.E.; Micheli-Tzanakou, E. Chronic patient's management: The Copd example. In M-Health; Springer: Boston, MA, USA, 2006.

10. World Health Organization. Integrated Chronic Disease Prevention and Control. Available online: https://www.who.int/chp/ about/integrated_cd (accessed on 15 July 2019).

11. Wang, Z.X.; Shi, J.W.; Wu, Z.G.; Xie, H.L.; Yu, Y.F.; Li, P.; Liu, R.; Jing, L.M. Changes in chronic disease management among community health centers (CHCs) in China: Has health reform improved CHC ability? Int. J. Health Plan. Manag. 2017, 32, 317-328. [CrossRef] [PubMed]

12. Chen, X. Community health service and health management in the role of chronic diseases prevention and control analysis. Med. J. Liaoning 2017, 31, 41-42.

13. Lin, M. Comparative Analysis of the Status of Community Service Organizations in China; Tianjin University Finance and Economics: Tianjin, China, 2017.

14. Ling, Y. Ponderations on the development of promoting community health service based on health management of chronic disease. J. Anhui Univ. Technol. 2013, 30, 51-52.

15. Wong, E.L.Y.; Woo, J.; Hui, E.; Chan, C.; Chan, W.L.S.; Cheung, A.W.L. Primary care for diabetes mellitus: Perspective from older patients. Patient Prefer. Adher. 2011, 5, 491-498. [CrossRef]

16. Mallawaarachchi, D.S.V.; Wickremasinghe, S.C.; Somatunga, L.C.; Siriwardena, V.T.; Gunawardena, N.S. Healthy lifestyle centres: A service for screening noncommunicable diseases through primary health-care institutions in Sri Lanka. WHO South East Asia J. Public Health 2016, 5, 89-95. [CrossRef]

17. Kim, I.V.; Bochkareva, E.V.; Varakin, I.I.; Kokurina, E.V. Screening for chronic cerebrovascular diseases in primary health care facilities. Profil. Med. 2013, 16, 27-30.

18. Sharma, A.; Patnaik, R.; Garg, S.; Ramachandran, P. Detection \& management of anaemia in pregnancy in an urban primary health care institution. Indian J. Med. Res. 2008, 128, 45-51.

19. Donabedian, A. The quality of care. How can it be assessed? JAMA 1988, 260, 1743-1748. [CrossRef]

20. Wang, L.; Wu, H.; Chang, L.J.; Lin, K.K.; Liu, X.Y.; Wei, X.J.; Jiang, Y.R.; Chen, Y. Emergency management strategies of community health service agencies in the joint prevention and control of COVID-19. Nurs. Integr. Tradit. Chin. West Med. 2020, 6, 58-61.

21. Vedanthan, R.; Kamano, J.H.; DeLong, A.K.; Naanyu, V.; Binanay, C.A.; Bloomfield, G.S.; Chrysanthopoulou, S.A.; Finkelstein, E.A.; Hogan, J.W.; Horowitz, C.R.; et al. Community health workers improve linkage to hypertension care in Western Kenya. J. Am. Coll. Cardiol. 2019, 74, 1897-1906. [CrossRef]

22. Chen, W.L.; Zhang, C.G.; Cui, Z.Y.; Wang, J.Y.; Zhao, J.; Wang, J.W.; Wang, X.; Yu, J.M. The impact of social capital on physical activity and nutrition in China: The mediating effect of health literacy. BMC Public Health 2019, 19, 1713. [CrossRef] [PubMed]

23. Li, L.; Li, C.Y.; Zhou, Q.Y.; Wang, X.; Gao, X.; Tian, Z.; Chen, R.; Xu, T.Q.; Hao, C.; Chen, Z.; et al. Comprehensive analysis of maternal health management and monitoring mechanisms in Beijing and Shanghai. Chin. Health Serv. Manag. 2019, 36, 466-469.

24. Yan, Y.Y.; Pu, Y.; Zhang, Q.M.; Zhang, Y.Y.; Chen, C.Y.; Yang, X.; Li, L.; Hao, M.; Pu, C.; Chen, F. Degree of perfection in the management mechanism of infectious diseases prevention in Yunnan and Guangxi-A quantitative evaluation from the perspective of policy documents. Chin. Manag. Health Serv. Adm. 2020, 40, 53-58.

25. Li, L.; Li, C.Y.; Zhou, Q.Y.; Pu, C.; Xu, L.Z.; Xu, T.Q.; Hao, C.; Hu, Z.; Hao, M. Differences of maternal mortality rate between Shanghai and New York city from the perspective of regulatory policy. Chin. Med. J. 2020, 133, 792-799. [CrossRef]

26. Hao, M. Pursuing Excellence-Building an Appropriate Public Health System; CPC Central Party School Press: Beijing, China, 2021.

27. World Health Organization. Noncommunicable_Diseases. Available online: https://www.who.int/health-topics/ noncommunicable-diseases\#tab=tab_1 (accessed on 25 July 2019).

28. World Health Organization. ICD-11 for Mortality and Morbidity Statistics (ICD-11 MMS). Available online: https://icd.who.int/ browse11/1-m/en (accessed on 12 February 2020).

29. Regan, S.; Macdonald, M.; Allan, D.E.; Martin, C.; Peroff-Johnston, N. Public health human resources: A comparative analysis of policy documents in two Canadian provinces. Hum. Resour. Health 2014, 12, 13. [CrossRef]

30. Zhao, Y.H.; John, S.; Chen, X.X.; Wang, Y.F.; Gong, J.Q.; Meng, Q.Q.; Wang, G.W.; Wang, H.L. China Health and Retirement Longitudinal Study Wave 4 User's Guide; National School of Development, Peking University: Beijing, China, 2020. 
31. China Health and Retirement Longitudinal Survey, CHARLS. Available online: http://charls.pku.edu.cn/pages/about/charls / zh-cn.html (accessed on 13 September 2019).

32. Yuan, Y.Y.; Li, H.F. A study on the gender difference of falls among the elderly in urban and rural China: Based on CHARLS 2015 data. Popul. Soc. 2020, 36, 46-57. [CrossRef]

33. Zhang, L.Y.; Zhang, H.N. Financial constraints and family entrepreneurship-urban and rural differences in China. J. Financ. Res. 2013, 09, 123-135.

34. Qiu, Y.D.; Li, H.; Yang, Z.Y.; Liu, Q.; Wang, K.; Li, R.J.; Xing, D.; Hou, Y.F.; Lin, J.H. The prevalence and economic burden of pain on middle-aged and elderly Chinese people: Results from the China health and retirement longitudinal study. BMC Health Serv. Res. 2020, 20, 600. [CrossRef] [PubMed]

35. Hayes, A.F. Methodology in the social sciences. In Introduction to Mediation, Moderation, and Conditional Process Analysis: A Regression-Based Approach; Guilford Press: New York, NY, USA, 2013.

36. Efron, B.; Tibshirani, R.J. An Introduction to the bootstrap. J. Am. Stat. Assoc. 1993, 89, 436.

37. Kong, L.Z. Thoughts on chronic diseases prevention and control in China. Chin. Health Serv. Manag. 2012, 5, 2-5.

38. General Office of the State Council of the People's Republic of China. The General Office of the State Council on Printing and Distributing China's Medium- and Long-Term Plan for the Prevention and Treatment of Chronic Diseases (2017-2025). Available online: http:/ / www.gov.cn/zhengce/content/2017-02/14/content_5167886.htm (accessed on 14 February 2017).

39. Zhang, H.; Xiong, J.Y.; Guan, W.B.; Jiang, M.Z.; Shen, X.; Ma, J. Analyzing the management effects of chronic diseases: Taking national demonstration zone of chronic diseases comprehensive prevention and control as an example. Chin. Hosp. 2019, 23, 15-17.

40. Zhang, L. Evaluation on Diabetes Mellitus Management in Community Health Service; Jinan University: Jinan, China, 2015.

41. Chen, S.L. Research on the role of community health service agencies in the prevention and treatment of chronic diseases. Pract. J. Card. Cereb. Pneumal Vasc. Dis. 2011, 19, 514-515.

42. Wang, S.Z.; Luo, F.P. Grassroots policy mobilization: A new way to facilitate residents' participation. Nanjing J. Soc. Sci. 2020, 4, 63-71.

43. Feng, J.J.; Liu, Y.F.; Jing, R.F. International experience of chronic disease management and enlightenment. China Pharm. 2017, 28, 1009-1012.

44. Wu, Z.J.; Jian, W.Y. Availability of community health management services for elderly patients with chronic diseases and its social determinants. Chin. Gen. Pract. 2015, 18, 3469-3472.

45. Zhao, Y.R. Social Work Methods in the Social Support Network Construction for the Elderly-Taking the Practice of F Community Service Center in SHENZHEN as the Study Case; Suzhou University: Suzhou, China, 2014.

46. Li, J.L.; Li, J.J.; Jin, R.R.; Zhang, J.; Su, X.W.; Ma, S.; Deng, G.J.; Shen, Z.Z.; Bian, F.; Jiang, Y. Studying the difficulty degree of related activities in communities of the national demonstration areas for comprehensive prevention and control of non-communicable diseases. Chin. J. Prev. Control Chronic Dis. 2018, 26, 283-286.

47. Wang, J.; Li, N.X. The Influence of the elderly home care in community on the management of chronic diseases in the elderly. J. Prev. Med. Inf. 2017, 33, 1174-1177.

48. Li, L.Q. Analysis on the current situation of Dong zhangmeng rural health library. Chin. J. Clin. Ration Drug Use 2011, 4, 164-165.

49. Deng, Q.; Liu, W. Physical exercise, social interaction, access to care, and community service: Mediators in the relationship between socioeconomic status and health among older patients with diabetes. Front. Public Health 2020, 8, 589742. [CrossRef] [PubMed]

50. World Health Organization. Follow-up to the Political Declaration of the Third High-Level Meeting of the General Assembly on the Prevention and Control of Non-Communicable Diseases. Available online: https://apps.who.int/iris/handle/10665/328411 (accessed on 23 October 2019). 